\title{
Tree-ring reconstruction of the level of Great Salt Lake, USA
}

\author{
R Justin DeRose,' Shih-Yu Wang, ${ }^{2}$ Brendan M Buckley ${ }^{3}$ \\ and Matthew F Bekker ${ }^{4}$
}

\begin{abstract}
Utah's Great Salt Lake (GSL) is a closed-basin remnant of the larger Pleistocene-age Lake Bonneville. The modern instrumental record of the GSL-level (i.e. elevation) change is strongly modulated by Pacific Ocean coupled ocean/atmospheric oscillations at low frequency, and therefore reflects the decadalscale wet/dry cycles that characterize the region. A within-basin network of seven tree-ring chronologies was developed to reconstruct the GSL water year (September-August) level, based upon the instrumental record of GSL level from I876 to 2005. The result was a 576-year reconstruction of the GSL level that extends from I 429 to 2005 ; all calibration-verification tests commonly used in dendroclimatology were passed. The reconstruction explains $48 \%$ of the variance in the instrumental GSL level and exhibits significant periodicity at sub-decadal scales over the past six centuries. Meanwhile, predominance of multi-decadal periodicity in the early half of the record shifted to quasi-decadal dominance in the latter half, and this is consistent with that of proxy reconstructions of the Pacific Decadal Oscillation. The GSL-level reconstruction is a crucial component to improving our insight into the possible controls of coupled ocean-atmosphere interactions on precipitation delivery.
\end{abstract}

\section{Keywords}

decadal oscillation, dendroclimatology, drought cycle, Great Basin, paleohydrology, pluvial

Received 4 October 2013; revised manuscript accepted 20 February 2014

\section{Introduction}

Lake-level fluctuation of closed-basin lakes in semi-arid regions is an important indicator of local climate variability (Wang et al., 2012). Closed-basin lakes act as virtual rain gages and evaporation pans for their associated watersheds, integrating spatial and temporal variability of the rather noisy pattern of precipitation throughout the watershed. Large lakes directly record the balance of inflow and evaporation and, therefore, reflect any persistent wet/dry periods. Situated in the eastern Great Basin of the United States, the Great Salt Lake (GSL) is a closed-basin remnant of the giant Pleistocene lake - Lake Bonneville (Figure 1). The GSL is shallow (no deeper than $30 \mathrm{~m}$ ) and expansive (covering at least $4400 \mathrm{~km}^{2}$ ), and its level integrates the marked spatial difference of precipitation between valleys and mountains, dampens out high-frequency variation, and records primarily decadal-scale variability (Lall and Mann, 1995). By retaining this low-frequency information, the instrumental record of GSL elevation (hereafter GSL level) has emerged as a crucial component for understanding regional water resources and climate predictions on decadal-tomulti-decadal timescales.

The impact of El Niño-Southern Oscillation (ENSO) on precipitation anomalies and drought over the western United States has been studied extensively. It is now well established that ENSO tends to produce the so-called North American dipole encompassing the Pacific Northwest and the Southwest with opposite polarity in precipitation anomalies (Dettinger et al., 1998 and subsequent works). However, past studies (Rajagopalan and Lall, 1998; Zhang and Mann, 2005) have noted that the central part of the western United States (e.g. the GSL watershed) is shielded from direct influence of ENSO as the region lies between the marginal zone of ENSO's north-south dipole pattern. Later studies
(Brown, 2011; Hidalgo and Dracup, 2003) also found that the ENSO-climate connection in the western United States is not stable; rather, it fluctuates following a long-term oscillatory manner, likely controlled by the Pacific Decadal Oscillation (PDO; Wang and Gillies, 2012).

Previous power spectral analysis of the GSL-level variation revealed predominant quasi-decadal (10-15 years) and multidecadal ( $\sim 30$ years) frequencies (Wang et al., 2010, 2012). These 10- to 15-year and 30-year frequencies coincide with the Pacific Quasi-Decadal Oscillation (QDO; Hasegawa and Hanawa, 2006; Tourre et al., 2001; Wang et al., 2011) and the Interdecadal Pacific Oscillation (IPO; Folland et al., 2002), respectively. Previous studies by Wang et al. $(2010,2011,2012)$ indicated that within the QDO and IPO framework, the hydrological factors controlling the GSL level (like precipitation and streamflow) respond to a particular atmospheric teleconnection that is induced at the transition point of those oscillations. The transition lies approximately halfway between the warmest and coldest sea surface temperature (SST) anomalies in the tropical Central Pacific, producing a transPacific short-wave train. This short-wave train generates an

\footnotetext{
'Rocky Mountain Research Station, USA

2Utah State University, USA

${ }^{3}$ Columbia University, USA

${ }^{4}$ Brigham Young University, USA

\section{Corresponding author:}

$R$ Justin DeRose, Forest Inventory and Analysis, Rocky Mountain Research Station, 507 25th Street, Ogden, UT 8440I, USA.

Email: rjustinderose@gmail.com
} 


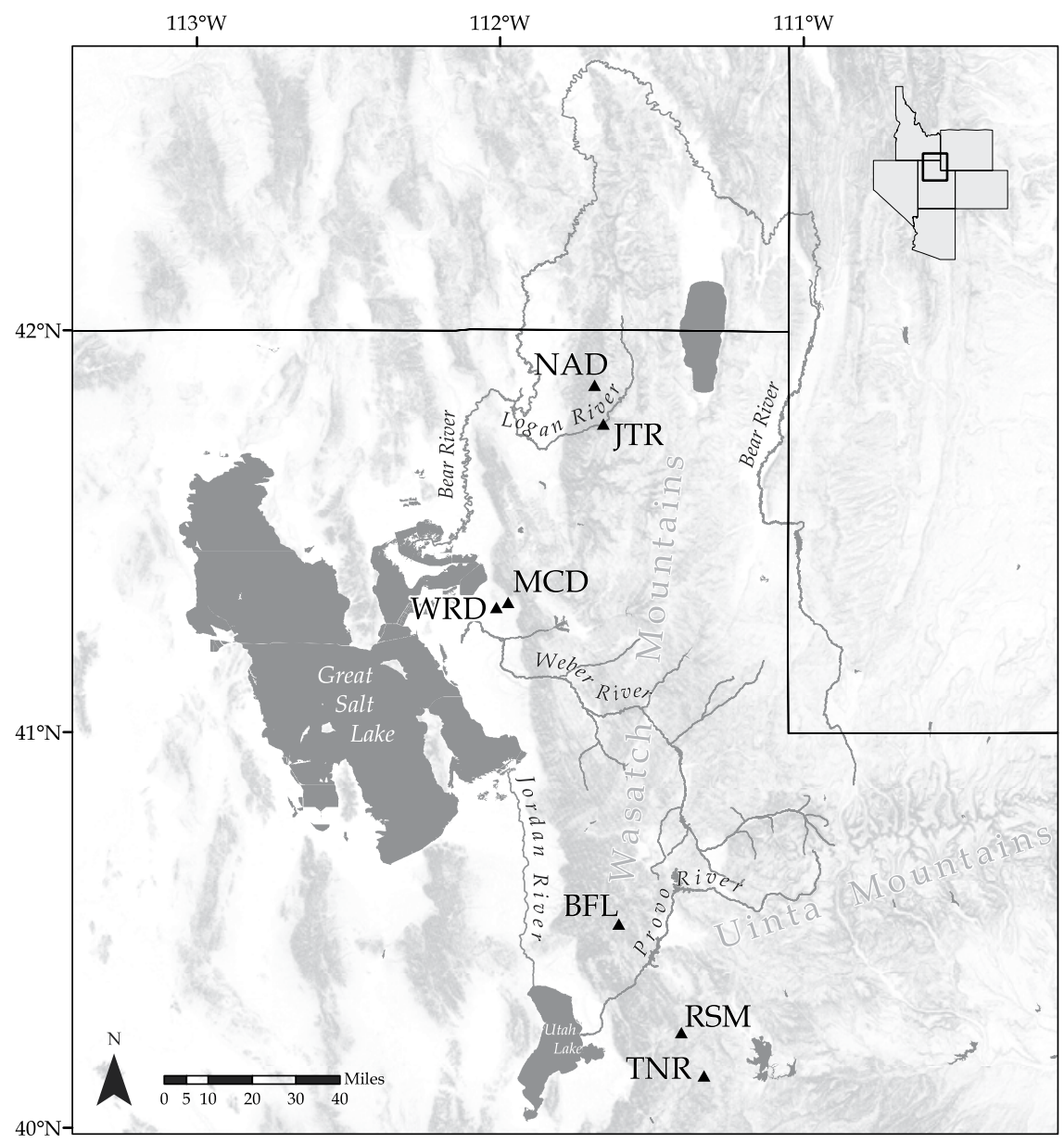

Figure I. Map of study region centered on Great Salt Lake watershed showing major tributaries and seven tree-ring sites that were used in the model.

anomalous trough (ridge) over the Gulf of Alaska during the warm-to-cool (cool-to-warm) transitions of the QDO/IPO oscillations, subsequently enhancing (reducing) precipitation in the GSL watershed. This knowledge has been applied to develop a forecast model that predicts the GSL-level change out to 8 years (Gillies et al., 2011). Furthermore, tree-ring-reconstructed precipitation data over northeastern Utah (Gray et al., 2004) not only supported the QDO and IPO influences on the GSL but also suggested possible longer cycles (Wang et al., 2010) that are difficult to verify within the short instrumental data period.

It has been demonstrated that tree-ring chronologies can be an effective proxy for lacustrine levels (Quinn and Sellinger, 2006; Wiles et al., 2009). In this paper, we use tree-ring data to extend the GSL-level record into the past. Like streamflow reconstructions based on tree rings, the relationship between GSL lake level and tree-ring increment is indirect. To further complicate this indirect relationship, the amount of precipitation necessary to increase lake level likely increases exponentially given the large, shallow nature of the GSL basin. Although small changes in absolute elevation result in large changes in surface area (Morrisette, 1988), the increased area is subjected to increased summertime evaporation, effectively dampening lake levels (Currey et al., 1984). However, the relatively small year-to-year elevation changes ought to reflect annual precipitation delivery to the basin because GSL transpiration balances inflow by late summer (Currey et al., 1984).

We investigate the response of tree-ring width increment to precipitation fluctuations integrated by the GSL level, and explore the usage of this response in reconstructing the GSL level. This rationale has been tested for streamflow models within the GSL basin (Allen et al., 2013; Bekker et al., forthcoming), and for nearby watersheds such as Colorado (Woodhouse et al., 2006) and northeastern Utah (Carson and Munroe, 2005), as well as for lake-level reconstructions (Meko, 2006). In this study, we (1) develop a GSL-level reconstruction using multiple tree-ring chronologies as predictors, (2) use the reconstruction to characterize regional droughts and pluvials, (3) test the veracity of the reconstruction by comparing it with recent streamflow reconstructions of major GSL tributaries, (4) subject the GSL reconstruction to an examination of possible multi-decadal periodicity, and (5) use the GSL reconstruction to explore regional climate dynamics.

\section{Methods}

\section{GSL level}

Following the GSL prediction model built from instrumental records by Gillies et al. (2011), we focused the reconstruction effort on the first differencing of GSL level (i.e. water year minus previous water year) to capture the hydrologic input of the lakelevel change; the differencing also serves to normalize the timeseries. Because regional precipitation delivery is dominated by cold season storms originating in the Pacific Ocean that bring moisture as snow, and the distribution of monthly precipitation for the region is rather uniform between January and March, water year (September-August) data effectively characterize the hydroclimate. For the dependent variable, we used the GSL water year record from 1876 to 2005, available from the United States Geological Survey (http://waterdata.usgs.gov/ut/nwis/uv/?site no $=10010000)$. Although GSL level has been estimated back to 1848 , we only used the data after 1876 when direct physical measurement began. 
Table I. Attributes of the tree-ring chronologies used for the GSL reconstruction.

\begin{tabular}{|c|c|c|c|c|c|c|c|}
\hline Sites & Species & Elevation $(\mathrm{m})$ & Time-span & Inter-series correlation & Average mean sensitivity & Number trees & Mean series length \\
\hline BFL & Pinus flexilis & 3000 & $351-2006$ & 0.55 & 0.176 & 73 & 381 \\
\hline JTR & Juniperus scopulorum & 2100 & $1227-2010$ & 0.605 & 0.227 & 47 & 397 \\
\hline MCD & Pseudotsuga menziesii & 2133 & $1370-2012$ & 0.691 & 0.248 & 87 & 333 \\
\hline NAD & P. menziesii & 2730 & $1274-2010$ & 0.595 & 0.174 & 49 & 431 \\
\hline RSM & Pinus edulis & 2130 & $|428-20| \mid$ & 0.688 & 0.311 & 52 & 282 \\
\hline TNR & P. edulis & 1960 & $|3| 3-20||$ & 0.733 & 0.307 & 55 & 381 \\
\hline WRD & P. menziesii & 2300 & || $33-20||$ & 0.592 & 0.213 & 55 & 475 \\
\hline
\end{tabular}

GSL: Great Salt Lake.

\section{Reconstruction procedure}

Increment cores from multiple sites within the GSL watershed were collected from 2010 through 2012 following common protocols (Speer, 2010; Stokes and Smiley, 1968). From these sites, seven were ultimately chosen for modeling based on their length ( $>500$ years) and their depth ( $>40$ trees) and included multiple species from across a large range of elevation (Table 1 and Figure 1). Site-specific chronologies were developed by crossdating individual series using the marker year method (Yamaguchi, 1991). The precision of crossdating for all tree-ring chronologies was verified using the program COFECHA (Holmes, 1983), a quality control protocol that ensures proper assignment of calendar years to each and every growth ring. Prior to model-building, all tree-ring series were detrended using a 100-year cubic smoothing spline (Cook and Peters, 1981) to accentuate highfrequency variability in ring width pattern before calculating a biweight robust mean for each year to minimize the effects of individual extreme years on the estimation of the mean (Cook and Kairiukstis, 1990).

A total of 21 predictor variables ( 7 chronologies plus their $n$ -1 and $n+1$ lags) were screened based on the significant relationship ( $p<0.05$, two-sided) with the dependent variable (GSL level). As is common in streamflow reconstructions, we allowed $n-1$ and $n+1$ lags to be considered as predictors in the model. Given the inherent growth-related persistence found in tree-ring chronologies (Cook and Kairiukstis, 1990) and the low-frequency signal found in the GSL level, time-lagged predictors potentially increase predictive model skill. We used a principal components (PCs) regression analysis approach that reduces the chronologies to their primary mode of variability; this minimizes the possibility of over-fitting compared with, for example, a straightforward multiple regression. An eigenvalue cutoff greater than or equal to 1 was used to screen predictors for the final model. A stepwise regression approach that minimized Akaike Information Criterion (Burnham and Anderson, 2002) was used to determine final predictors in the model. Rigorous split calibration/verification procedures were performed on early (1876-1940) and late periods (1941-2005) before building a full-model calibration on the total period (1876-2005). Calibration/verification was assessed via the reduction of error (RE) and coefficient of efficiency (CE) on first differenced results as discussed in Cook and Kairiukstis (1990). The sign test, a tabulation of correspondent year-to-year changes between the observed data and the reconstruction, was used to assess model fit. Model skill was described using $r^{2}$ and adjusted $r^{2}$, and the potential residual autocorrelation was assessed with the Durbin-Watson statistic (Draper and Smith, 1998).

Year-to-year extremes of high (low) GSL level were tabulated to characterize possible pluvial (drought) conditions. We correlated the reconstructed lake level with recently developed streamflow reconstructions (Allen et al., 2013; Bekker et al., forthcoming) for two important tributaries to the GSL in order to verify correspondence and to elucidate possible sub-regional differences in precipitation. Wavelet analysis was used to explore the spectral properties of the reconstructed time-series (Torrence and Compo, 1998).

\section{Climate diagnostics}

Given the significant, yet inverse correlations of the multidecadal variations between the GSL level and the IPO found in instrumental records (Wang et al., 2012), it is of interest to examine the stationarity of the GSL-IPO relationship during the past half millennium. However, to address this question, a reconstruction of the IPO is needed, which is currently nonexistent. Therefore, we adopted two tree-ring-based reconstructions of the PDO index (Biondi et al., 2001; MacDonald and Case, 2005) covering the period 993-1996 as surrogates, given the shared spectral power between PDO and IPO (the annual-mean PDO and IPO indices are correlated $r=0.67$ during the 1900-2010 period, data not shown). While the PDO was defined as the first PC of the North Pacific sea surface temperature anomalies (SSTAs north of 20N (Mantua et al., 1997), the IPO represents the first PC of SSTA over the entire Pacific Basin (e.g. Folland et al., 2002). Their difference mainly lies in the tropical loading of SSTA and the fact that the IPO contains slightly higher power in the interannual frequency; 30-year running correlations were calculated between the GSL reconstruction and PDO. From a sampling point of view, the low-frequency variability in running correlations between any pair of climatic time-series often contains apparent periodicities; this is known as the 'Slutsky-Yule effect' (Wunsch, 1999) and one that may result in pseudo-physical explanations for stochastic noise (Gershunov et al., 2001). Thus, to examine the fluctuations revealed from the 30 -year running correlations, we also computed the 100 -year running correlation for the GSL and PDO reconstructions.

\section{Results}

\section{GSL watershed}

The original pool of 21 predictors was reduced to 13 based on their relationship with the dependent variable. Among the 13 retained predictors, JTR (Table 1) was the only site not represented in the final model (Figure 1). PCs analysis of the 13 predictors resulted in five components with an eigenvalue $>1$, of which four were chosen for the final model based on stepwise regression. The final GSL model explained $48 \%$ of the variance in the historical GSL record (Figure 2). The reconstruction passed all common calibration-verification schemes (Table 2), including tests for RE and CE, the latter of which is extremely difficult to pass (see Cook and Kairiukstis, 1990). The first differenced tests indicated strong temporal fidelity in the GSL model over the measurement period. However, the model did not capture the magnitude of either the early 1980s pluvial or the ensuing 1987 draining of the lake via pumping, which was unprecedented (in the historical record). Yet, the model closely followed the patterns of GSLlevel change as indicated by the sign test (Table 2). 


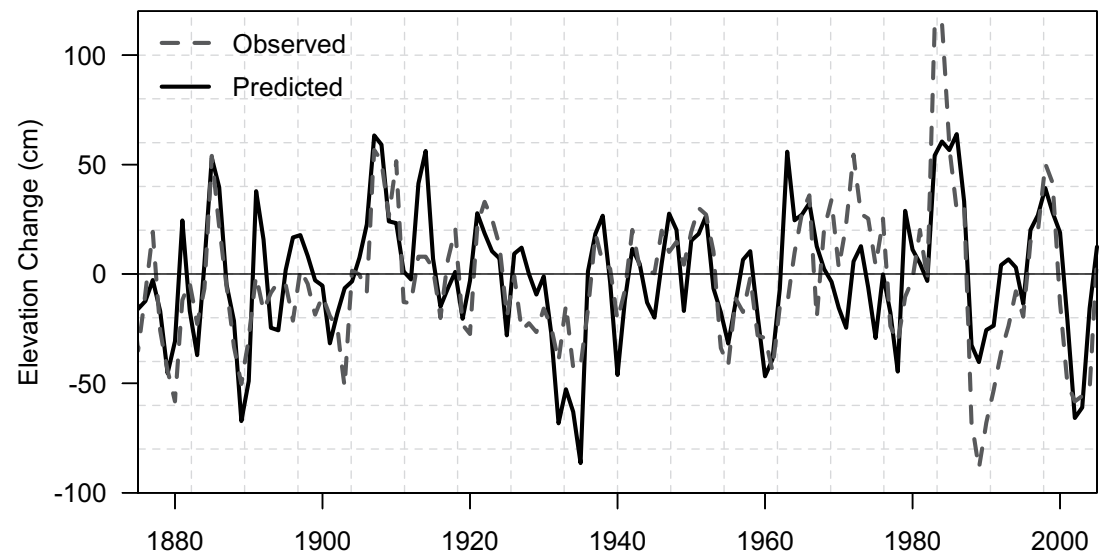

Figure 2. Observed Great Salt Lake (GSL) first differenced water year level (cm) for the period 1876-2005 and predicted GSL level.

Table 2. Statistics for the Great Salt Lake reconstruction model.

\begin{tabular}{lllllll}
\hline Calibration (verification) period & $R^{2}$ & Adjusted $R^{2}$ & RE & CE & Sign test & Durbin-Watson \\
\hline 1876-1940 & 0.53 & 0.51 & $0.53(0.37)$ & $0.53(0.37)$ & $48+/ 17-(44+/ 20-)$ & 1.52 \\
$(194 \mid-2005)$ & & & $0.43(0.20)$ & $0.35(0.20)$ & $48+/ 17-(43+/ 17-)$ & \\
$1941-2005$ & 0.50 & 0.49 & $0.49(0.24)$ & $0.49(0.24)$ & $49+/ 16-(39+/ 25-)$ & 1.44 \\
$(1876-1940)$ & & & $0.36(0.24)$ & $0.21(0.24)$ & $42+/ 23-(39+/ 25-)$ & 1.36 \\
Full model 1876-2005 & 0.49 & 0.48 & & & & \\
\hline
\end{tabular}

RE: reduction of error; CE: coefficient of efficiency.

Values in parenthesis are from first differenced test.

Full reconstruction model: $0.1426 \times \mathrm{BFL}_{+1}+0.0226 \times \mathrm{MCD}_{-1}+0.1008 \times \mathrm{MCD}+0.0434 \times \mathrm{MCD}_{+1}+0.1206 \times \mathrm{NAD}+0.104 \mathrm{I} \times \mathrm{NAD}+1+0.201 \mathrm{I} \times$

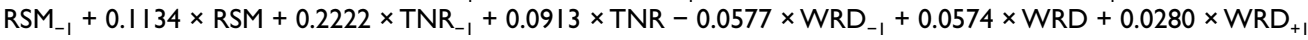

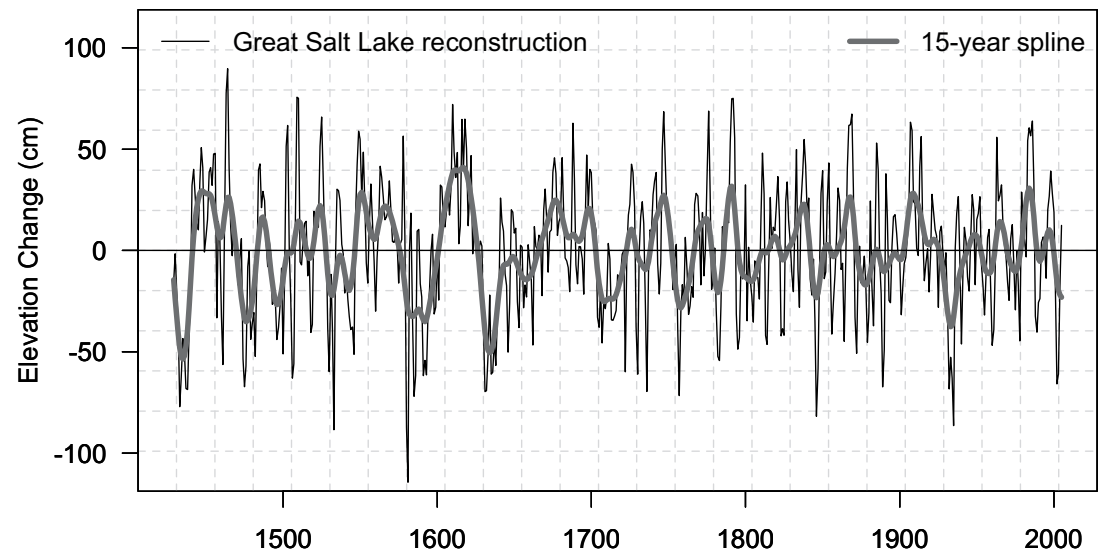

Figure 3. Reconstructed Great Salt Lake water year level for the period 1429-2005. Bold line is a 15-year cubic smoother applied to the reconstructed time-series with $50 \%$ frequency cutoff to accentuate the quasi-decadal variability indicated by the wavelet analysis. Expressed population signal $<0.85$ cutoff occurs at 1505 .

The GSL reconstruction extended 576 years, from 1429 to 2005 (Figure 3), which provided a multi-centennial perspective to assess the long-term variability of the GSL level. Tabulation of the 15 most severe wet and dry individual years (Table 3) revealed that the GSL reconstruction tracked known historic droughts (e.g. 1846, 1932, 1935, and 2000-2001) and historic pluvials (e.g. 1907 and 1986). More interestingly, the reconstruction indicated the vast majority of wet and dry years occurred prior to the historical record. For example, the driest (wettest) year on record, 1581 (1464) occurred many centuries ago and was substantially larger in magnitude than the historical record. At lower frequencies, the GSL lake-level reconstruction revealed large, multi-year reductions in lake levels from $1580-1600$, in the 1630 s, and from $1700-1710$ that in each case were at least as severe as the known lake-level minima during the drought of the 1930s and 2000-2001 (Figure 3). Similarly, the pluvials during the mid-1550s, early 1600 s, and 1740 s exceed in intensity the pluvials of the early 1900s and the 1980s (Figure 3).

Significant relationships between reconstructed GSL level and (1) the Logan River reconstruction $(r=0.41)$ and (2) the Weber River reconstruction ( $r=0.61$; Figure 4$)$ indicated relatively strong spatial coherence in water year precipitation delivery for the region. Matching individual dry years were found in regional streamflow reconstructions, such as 1846 (Logan) and 1845-1846 (Weber). However, sub-regional differences were apparent between the GSL and the two rivers, in particular at lower frequencies (Figure 4). For example, in the mid-17th century, only the Weber reconstruction tracked closely with the GSL, but not the Logan reconstruction (Figure 4). Similarly, the Logan River reconstruction did not indicate the same intensity of the early 1630 s pluvial as that in the Weber and GSL reconstructions. 
Wavelet analysis of the reconstructed GSL level (Figure 5) revealed that the pattern of the decadal-scale oscillations changed over time. The earlier part of the data (1429-1700) exhibited predominant 30 - to 60 -year periodicity, whereas the post-1700 data revealed stronger 10 - to 15 -year periodicity. Also, the juxtaposition of both $\sim 30$ - to 60 -year and $\sim 10$ - to 15 -year periodicity persisted until 1600 and was missing in the latter half of the reconstruction (Figure 5). The $\sim 30$ - to 60 -year periodicity in the pre-1700 period indicated that prolonged and intensive drought cycles were likely a common feature in the GSL watershed (Figures 3 and 5).

\section{Climate diagnostics}

Both PDO reconstructions (Biondi et al., 2001; MacDonald and Case, 2005) revealed similar fluctuations of running correlations with the GSL level, showing periodic episodes of significant correlations after 1650 (Figure 6a). Significantly negative correlations only appeared during the late 1500 s to late 1700 s. In

Table 3. Fifteen lowest and highest individual years of the 576 -year GSL reconstruction.

\begin{tabular}{llll}
\hline Year & Lowest & Year & Highest \\
\hline 1581 & -114.286 & 1464 & 89.763 \\
1533 & -88.404 & 1463 & 77.584 \\
1580 & -87.283 & 1509 & 75.597 \\
1935 & -86.379 & 1510 & 75.152 \\
1846 & -81.751 & 1792 & 75.065 \\
1433 & -77.081 & 1791 & 74.966 \\
1585 & -71.903 & 1610 & 72.048 \\
1757 & -71.601 & 1776 & 68.806 \\
1631 & -69.603 & 1747 & 68.551 \\
1736 & -69.527 & 1869 & 67.322 \\
1632 & -69.142 & 1525 & 65.911 \\
1438 & -68.584 & 1618 & 64.907 \\
1932 & -68.243 & 1616 & 64.681 \\
1437 & -68.050 & 1986 & 63.949 \\
1889 & -67.239 & 1907 & 63.302 \\
\hline
\end{tabular}

GSL: Great Salt Lake.

Boldfaced values indicate historical measurement record. contrast, 100-year running correlations showed a different pattern, which suggested a 'regime change' in the relationship between GSL and PDO. The relationships shifted from insignificant between 1500 and 1750 to significant after 1750 to the mid20th century (Figure 6b).

\section{Discussion}

This study represents the first attempt at dendroclimatological characterization of the GSL level. Like most tree-ring-based reconstructions, there are limitations to the inference drawn from the data. For example, our parsimonious PCs derived model accounted for roughly half the variation in year-to-year GSLlevel changes, and we suggest at least three reasons for this: (1) additional and/or better predictors are needed to improve the reconstruction, (2) spotty tree-ring data are inherently limited in explaining the full variation of spatiotemporally integrated precipitation over a large basin, and/or (3) the indirect relationship between changing lake levels and tree-ring increment are too loosely coupled. However, it is important to note that our reconstruction was similar to those found in other tree-ring-based lakelevel reconstructions (36-50\% variance explained, Meko, 2006; Quinn and Sellinger, 2006). Regardless of these issues, the GSL reconstruction provides invaluable information for water resource variability for over half a millennia, enhances regional climate diagnostics, and adds to the paltry list of paleoclimate data sets for the Intermountain West.

While the year 1581 exhibited the most severe single-year drought on record, the low-frequency pattern suggests that the 1630-1640s exhibited the most extended period of dry conditions, not including the beginning of the reconstruction (1430s). It appears that drought conditions more intense and longer lasting had characterized the 300 years before 1750 . While the 1930 s was a severe drought in the GSL region and continentally (Stahle et al., 2007), it was relatively short compared with the 1580 s, $1630 \mathrm{~s}$, and early $1700 \mathrm{~s}$ droughts. The $1580 \mathrm{~s}$ mega-drought (Stahle et al., 2000) is also visible in the reconstruction, but that drought was rivaled by the 1630s drought in the GSL watershed (Figure 3). These observations shed light on a new possible historical context for extreme drought conditions and corroborate the previously documented existence of larger and longer paleodroughts (Barnett et al., 2010; Gray et al., 2004, 2011). Characteristics of both the intensity and magnitude of reconstructed drought
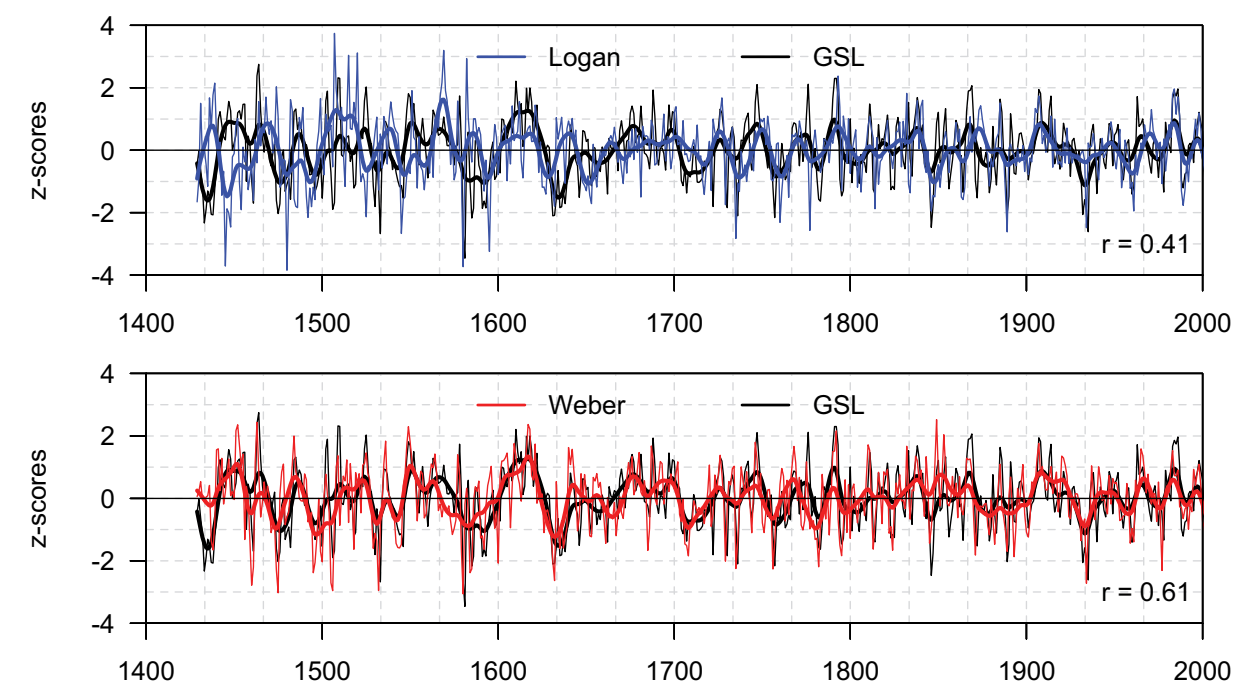

Figure 4. Comparison of reconstructed Great Salt Lake (GSL) level and (top) Logan River streamflow reconstruction, and (bottom) Weber River streamflow reconstruction, both tributaries to the Great Salt Lake basin. Expressed population signal $<0.85$ cutoff for Logan River occurs at $\sim 1610$. Low-frequency lines are 15-year low-pass filters with a 50\% frequency cutoff. Pearson product-moment correlation with GSL noted in lower right corner. 


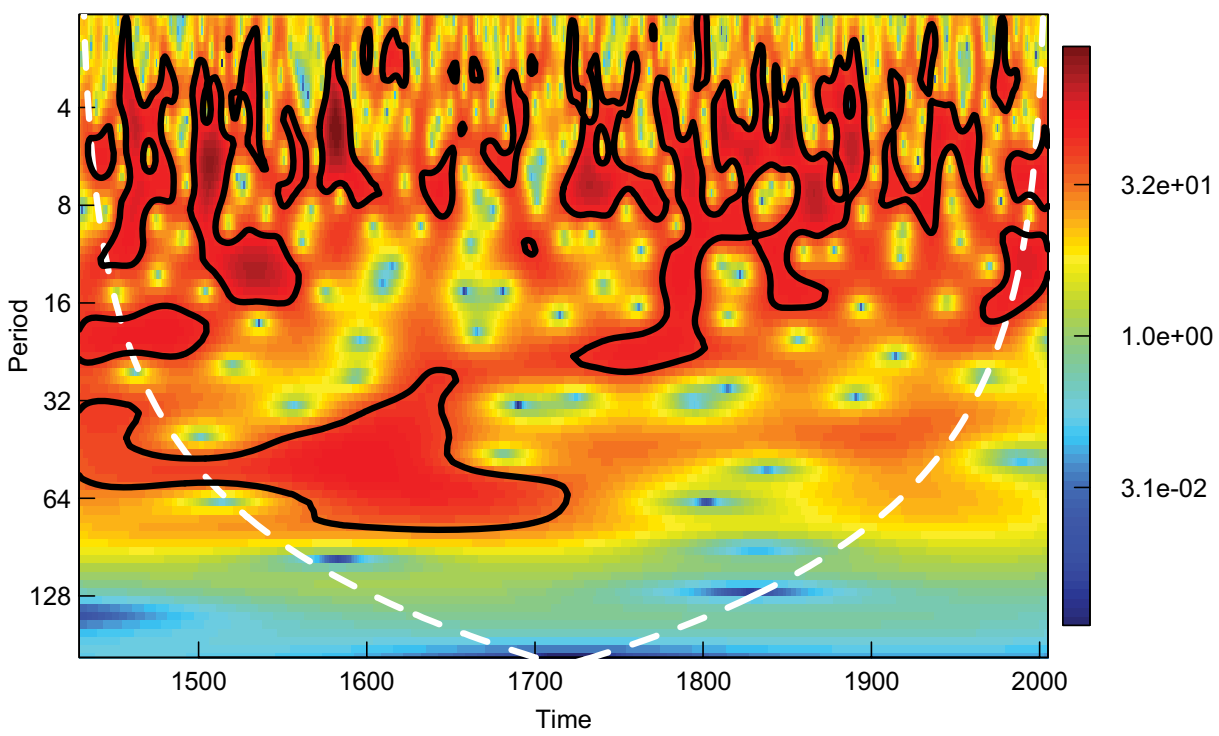

Figure 5. Wavelet power spectrum analysis of the reconstructed Great Salt Lake level (1429-2005) showing significance (alpha $<0.05$, outlined in black), and the cone of influence (white dashed line), outside which interpretation is not suggested.

(a) 30-year running correlation

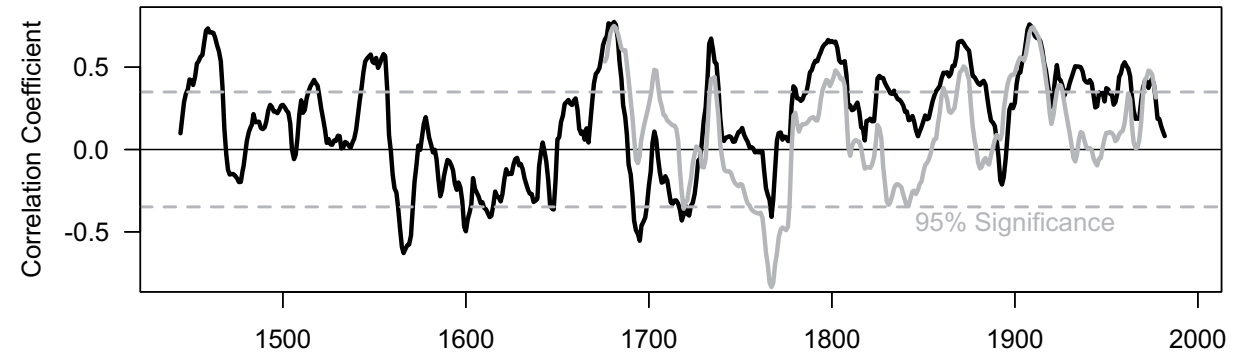

(b) 100-year running correlation

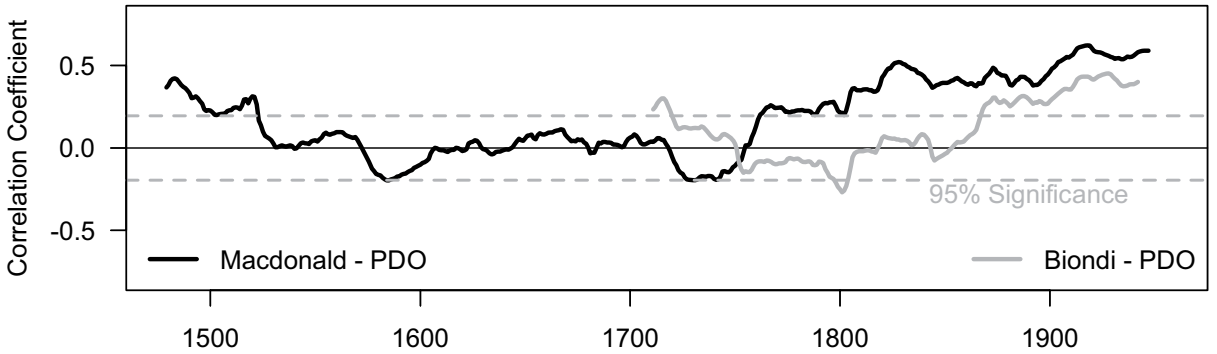

Figure 6. Running correlation analysis for (a) 30 years and (b) 100 years between GSL level and two PDO reconstructions (Biondi et al., 200I; MacDonald and Case, 2005).

GSL: Great Salt Lake; PDO: Pacific Decadal Oscillation.

events or periods could be incorporated into contemporary water management to bolster risk assessment.

By contrast, multi-year infilling and lake-level increase were most pronounced from 1600 to 1625 during what appears as the largest pluvial event in the record (Figure 3). The next largest 'wet' event in the historical record was the early 1900s pluvial, which was less severely wet than the early 17th century and even less so when compared with the modern analog, the 1980s pluvial. This rare, striking pluvial event was evident in all individual predictor chronologies, which suggested regional similarities in synoptic/weather forcing that created the wet conditions. Notable high lake levels during 1983-1986 (see Morrisette, 1988) provided an analogy with which to compare the GSL reconstruction. Our reconstruction reveals as many as seven previous pluvial events that are at least as large as the 1980s event. In particular, the early 1600s appear to record the largest pluvial of the last five centuries (Figure 3).
While historic lake levels have reached as high as $1283.8 \mathrm{~m}$, Currey et al. (1984) suggested that the GSL has filled to within 1 $\mathrm{m}$ of the Salt Lake International Airport runway elevation $(\sim 1285.3 \mathrm{~m}$ a.s.l.) at least twice in the last 3000 years, with the latter of those high levels putatively occurring in the 1670-1700 period, based on radiocarbon dates of sediment (Miller et al., 2005). Based on the annual resolution GSL tree-ring reconstruction, we suggest that this extreme lake level most likely occurred in the first half of the 17th century, a few decades earlier than 1670. Based on this timing, a pre-1630 high-GSL event would have been more probable than $\sim 1670$ suggested by Miller et al. (2005), given the cooler 'Little Ice Age' (LIA; Houghton et al., 1990) conditions prior to 1670 that reduced evapotranspiration. The GSL reconstruction indicated a new 'high level' that was likely much higher than the 1980 s event, which had triggered the state of Utah to install expensive pumping facilities. Regional 
water resource managers should be aware of the possibility that GSL levels could rise much higher than were seen in 1986-1987.

Year-to-year changes in GSL level closely aligned with drought/pluvial events recorded in regional streamflow reconstructions and, upon closer examination, revealed intra-regional differences unique to individual drainages. The Logan River is a major tributary to the Bear River, which in turn is the single largest contributor to the GSL. The Weber River is also a major contributor to the GSL, and the rivers originate in adjacent watersheds (Figure 1). The strong relationships between GSL level and both river reconstructions provided evidence that there was relatively strong spatial coherence in the delivery of precipitation during the water year over the entire region. However, sub-regional differences do exist between the GSL and the two rivers. The implication is that the center of pluvial activity migrates around the basin, sometimes more prominent in the north (Logan River) than in the south (Weber River) and vice versa (sensu Allen et al., 2013). This is also an indication that the geographic range of tree-ring sampling sites (Figure 1) reflects the changing rainfall distributions from year-to-year, and decade-to-decade.

The significant periodicity at sub-decadal timescales revealed by the wavelet analysis was persistent throughout the time-series and likely reflects the correspondence between the known association between the GSL level and the Pacific QDO and IPO (Wang et al., 2010, 2012). Interestingly, the shift from strong 30to 60 -year periodicity to more quasi-decadal variability occurred around the approximate end of the most severe temperature trough associated with the LIA. Whether this reflects regional conditions such as diminishing cloud cover (i.e. increasing evaporative demand) or extra-regional forcing (i.e. Pacific Ocean SST changes) is subject to further scrutiny.

The 30-year running correlation analysis indicated generally positive but marginally significant relationships between reconstructed GSL level and both PDO indices, in particular after the mid-1750s (Figure 6). However, prior to then, the relationship between GSL and PDO was less clear. Furthermore, comparing both running correlations with the wavelet spectra (Figure 5) suggests a concurrence between the change in the GSL-PDO correlations and the shift in GSL's periodicity near c. 1700. First, the low-frequency variability apparent in the 30 -year GSL-PDO relationship (Figure $6 a$ ) strongly mirrors the $\sim 10$ - to 15 -year periodicity in the wavelet spectra (Figure 5). Second, the long period of low correlations from the mid-1550s to $\sim 1700$ in both the 30 -year and 100-year running correlations are concurrent with the $\sim 30$ - to 60 -year periodicity in the GSL reconstruction (Figure 5). Such a shift in climate regime is intriguing and can only be elaborated through sophisticated climate model experiments.

Using a large quantity of tree cores $(>500)$ collected throughout Utah dating back to 1750, DeRose et al. (2013) found that the borderline of the ENSO dipole revealed considerable latitudinal fluctuation over the past three centuries. The fluctuation followed what seems to be a multi-decadal oscillation of 30-50 years, during which the state of Utah either was bifurcated by the borderline of the ENSO dipole or was completely engulfed by the El Niño regime (i.e. whereby El Niño would increase precipitation, as is the case for Arizona and New Mexico). Wang and Gillies (2012) found that such meridional fluctuation of the borderline of the ENSO-precipitation correlation in the GSL region is modulated by the PDO. Furthermore, the fluctuations in the running correlations (Figure 6) detailed the regional impact of the constructive and destructive phase overlaps between the PDO and ENSO over the western United States (e.g. Brown and Comrie, 2004; Dettinger et al., 1998).

Finally, it appears that lower frequency variability is inherent in the GSL-PDO relationships. For example, the running correlations appear to increase early in the record, prior to 1500 . Wang et al. (2010) have noted that the decadal variability of northeastern Utah's reconstructed precipitation (back to 1300) increases (decreases) following the positive (negative) phases of 150-year variability. Whether or not the low-term change of the GSL-PDO relationship is connected to such 150 -year variability requires future analysis and longer data.

\section{Conclusion}

Annually resolved tree-ring data collected within the GSL watershed allowed us to reconstruct the GSL level from 1429 to 2005 , a 576-year record. Results from the calibration/verification procedures determined the temporal fidelity of the reconstruction and suggested that annual variability of the GSL level was adequately reproduced. Strong coherence with regional streamflow reconstructions indicated that northern Utah generally exhibits a synchronous hydroclimatology; however, intra-regional differences were evident and likely reflect variability in precipitation delivery or the shifting influence of the ENSO dipole on precipitation patterns. Pronounced wet/dry periodicity was revealed by spectral analysis of the GSL reconstruction, which indicated that $\sim 30$ - to 60 -year variability was prevalent prior to $\sim 1700$, and $\sim 10$ - to 15 -year variability prevalent from 1700 to current. The shift of this regime change appeared to coincide with the peak in LIA conditions. Regardless, both periodicity regimes were characterized by severe reductions and infilling of GSL level, which translated into drastic fluctuations between dry and wet conditions, respectively. Comparison between the GSL-level and PDO reconstructions indicated potentially shifting climate forcing for the region, and confirmed that PDO, or similar Pacific Ocean teleconnections, likely modulate the polarity of ENSO effects on precipitation delivery to northern Utah. The post-1750 dominance of the quasi-decadal variability in the GSL and streamflow reconstructions pointed to another important climate forcing of the Pacific QDO documented previously (Gillies et al., 2011; Wang et al., 2010, 2012). As an indicator of low-frequency precipitation regimes for northern Utah, the GSL reconstruction provides new insight to inform regional water resources management.

\section{Acknowledgements}

Field support by Eric Allen, Donovan Birch, Le Canh Nam, Chalita Sriladda, Bryan Tikalsky, Nathan Gill, Chelsea Decker, Joseph Naylor, Matthew Collier, Nguyen Thiet, Nguyen Hoai, Mandy Freund, Dario Martin-Benito, Roger Kjelgren, and Tammy Rittenour is greatly appreciated. The comments of two anonymous reviewers greatly improved our earlier manuscript. Agricultural Experiment Station, Utah State University. Approved as journal paper no. 8643. This paper was prepared in part by an employee of the US Forest Service as part of official duties and is therefore in the public domain.

\section{Funding}

We wish to thank the Wasatch Dendroclimatology Research (WADR) Group for helping to support this study. This is a contribution of the WADR Group. Lamont-Doherty contribution number 7767 .

\section{References}

Allen EB, Rittenour T, DeRose RJ et al. (2013) A tree-ring based reconstruction of Logan River streamflow, northern Utah. Water Resources Research 49: 8579-8588.

Barnett FA, Gray ST and Tootle GA (2010) Upper Green River Basin (United States) streamflow reconstructions. Journal of Hydrologic Engineering 15(7): 567-579.

Bekker MF, DeRose RJ, Buckley BM et al. (forthcoming) A 576year Weber River streamflow reconstruction from tree-rings for contemporary water resource risk assessment in the 
metropolitan Wasatch Front, Utah. Journal of the American Water Resources Association.

Biondi F, Gershunov A and Cyan DR (2001) North Pacific decadal climate variability since 1661 . Journal of Climate 14: 5-10.

Brown DP (2011) Winter circulation anomalies in the western United States associated with antecedent and decadal ENSO variability. Earth Interactions 15: 1-12.

Brown DP and Comrie AC (2004) A winter precipitation 'dipole' in the western United States associated with multidecadal ENSO variability. Geophysical Research Letters 31: L09230. DOI: 10.1029/2003GL018726.

Burnham KP and Anderson DR (2002) Model Selection and Multiple-Model Inference: A Practical Information Theoretic Approach. New York: Springer Verlag.

Carson EC and Munroe JS (2005) Tree-ring based streamflow reconstruction for Ashley Creek, northeastern Utah: Implications for palaeohydrology of the southern Uinta Mountains. The Holocene 15(4): 602-611.

Cook ER and Kairiukstis LA (1990) Methods of Dendrochronology: Applications in the Environmental Sciences. Boston, MA: Kluwer Academic Press.

Cook ER and Peters K (1981) The smoothing spline: A new approach to standardizing forest interior tree-ring width series for dendroclimatic studies. Tree-Ring Bulletin 41: $45-53$.

Currey DR, Atwood G and Mabey DR (1984) Major Levels of the Great Salt Lake and Lake Bonneville: Map 73. Salt Lake City, UT: Utah Geological and Mineral Survey.

DeRose RJ, Wang S-Y and Shaw JD (2013) Feasibility of highdensity climate reconstruction based on Forest Inventory and Analysis (FIA) collected tree-ring data. Journal of Hydrometeorology 14(1): 375-381.

Dettinger MD, Cayan DR, Diaz HF et al. (1998) North-south precipitation patterns in western North America on interannualto-decadal timescales. Journal of Climate 11: 3095-3111.

Draper NR and Smith H (1998) Applied Regression Analysis. New York: John Wiley \& Sons.

Folland CK, Renwick JA, Salinger MJ et al. (2002) Relative influences of the Interdecadal Pacific Oscillation and ENSO on the south Pacific Convergence Zone. Geophysical Research Letters 29(13): 21-1-21-4. Available at: http:// dx.doi.org/10.1029/2001GL014201.

Gershunov A, Schneider N and Barnett T (2001) Low-frequency modulation of the ENSO-Indian monsoon rainfall relationship: Signal or noise? Journal of Climate 14: 2486-2492.

Gillies RR, Chung O-Y, Wang S-Y et al. (2011) Incorporation of Pacific SSTs in a time series model toward a longer-term forecast for the Great Salt Lake elevation. Journal of Hydrometeorology 12(3): 474-480. Available at: http://dx.doi. org/10.1175/2010JHM1352.1

Gray ST, Fastie CL, Jackson ST et al. (2004) Tree-ring-based reconstructions of precipitation in the Bighorn Basin, Wyoming, since 1260 A.D. Journal of Climate 17: 3855-3865.

Gray ST, Lukas JJ and Woodhouse C (2011) Millennial-length records of streamflow from three major upper Colorado River tributaries. Journal of the American Water Resources Association 47(4): 702-712.

Hasegawa T and Hanawa K (2006) Impact of quasi-decadal variability in the tropical Pacific on ENSO modulations. Journal of Oceanography 62(2): 227-234.

Hidalgo HG and Dracup JA (2003) ENSO and PDO effects on hydroclimatic variations of the Upper Colorado River Basin. Journal of Hydrometeorology 4: 5-23.

Holmes RL (1983) Computer-assisted quality control in tree-ring dating and measurement. Tree-Ring Bulletin 43: 69-78.
Houghton JT, Callendar BA and Varney SK (1990) Varney Climate Change: The IPCC Scientific Assessment. Cambridge: Cambridge University Press.

Lall U and Mann ME (1995) The Great Salt Lake: A barometer of low-frequency climatic variability. Water Resources Research 31(10): 2503-2515.

MacDonald GM and Case RA (2005) Variations in the Pacific Decadal Oscillation over the past millennium. Geophysical Research Letters 32(8): L08703. Available at: http://dx.doi. org/10.1029/2005GL022478.

Mantua NJ, Hare SR, Zhang Y et al. (1997) A Pacific interdecadal climate oscillation with impacts on salmon production. Bulletin of the American Meteorological Society 78(6): 1069-1079. Available at: http://dx.doi.org/10.1175/15200477(1997)078<1069:APICOW>2.0.CO;2.

Meko DM (2006) Tree-ring inferences on water-level fluctuations of Lake Athabasca. Canadian Water Resources Journal 31(4): 229-248. Available at: http://dx.doi.org/10.4296/ cwrj3104229.

Miller DM, Oviatt CG, Dudash SL et al. (2005) Late Holocene highstands of Great Salt Lake at locomotive springs, Utah. In: 2005 Annual Meeting, Salt Lake City, UT, 16-19 October. Washington, DC: Geological Society of America.

Morrisette PM (1988) The rising level of the Great Salt Lake: Impacts and adjustments. Bulletin of the American Meteorological Society 69(9): 1034-1040. Available at: http://dx.doi. org/10.1175/1520-0477(1988)069<1034:TRLOTG $>2.0$ .CO;2.

Quinn FH and Sellinger CE (2006) A reconstruction of Lake Michigan-Huron water levels derived from tree ring chronologies for the period 1600-1961. Journal of Great Lakes Research 32(1): 29-39. Available at: http://www.glerl.noaa. gov/pubs/fulltext/2006/20060006.pdf.

Rajagopalan B and Lall U (1998) Interannual variability in western US precipitation. Journal of Hydrology 210: 51-67.

Speer JH (2010) Fundamental of Tree-Ring Research. Tucson, AZ: The University of Arizona Press.

Stahle DW, Cook ER, Cleaveland MK et al. (2000) Tree-ring data document 16th century megadrought over North America. Eos, Transactions American Geophysical Union 81(12): 121-125. Available at: http://dx.doi.org/10.1029/00EO00076.

Stahle DW, Fye FK, Cook ER et al. (2007) Tree-ring reconstructed megadroughts over North America since A.D. 1300. Climatic Change 83(1-2): 133-149.

Stokes MA and Smiley TL (1968) An Introduction to Tree-Ring Dating. Chicago, IL: The University of Chicago Press.

Torrence C and Compo GP (1998) A practical guide to wavelet analysis. Bulletin of the American Meteorological Society 79(1): 61-78. Available at: http://dx.doi.org/10.1175/15200477(1998)079<0061:APGTWA>2.0.CO;2.

Tourre YB, Rajagopalan B, Kushnir Y et al. (2001) Patterns of coherent decadal and interdecadal climate signals in the Pacific Basin during the 20th century. Geophysical Research Letters 28: 2069-2072.

Wang S-Y and Gillies RR (2012) Climatology of the US Intermountain west. In: Wang S-Y and Gillies RR (eds) Modern Climatology. Rijeka: InTech, pp. 153-176.

Wang S-Y, Gillies RR and Reichler T (2012) Multidecadal drought cycles in the Great Basin recorded by the Great Salt Lake: Modulation from a transition-phase teleconnection. Journal of Climate 25: 1711-1721.

Wang S-Y, Gillies RR, Hipps LE et al. (2011) A transition-phase teleconnection of the Pacific quasi-decadal oscillation. Climate Dynamics 36: 681-693.

Wang S-Y, Gillies RR, Jin J et al. (2010) Coherence between the Great Salt Lake level and the Pacific quasi-decadal oscillation. Journal of Climate 23: 2161-2177. 
Wiles GC, Krawiec AC and D'Arrigo RD (2009) A 265-year reconstruction of Lake Erie water levels based on North Pacific tree rings. Geophysical Research Letters 36(5): L05705. Available at: http://dx.doi.org/10.1029/2009GL0 37164.

Woodhouse CA, Gray ST and Meko DM (2006) Updated streamflow reconstructions for the upper Colorado River Basin. Water Resources Research 42: W05415.

Wunsch C (1999) The interpretation of short climate records, with comments on the North Atlantic and Southern Oscil- lations. Bulletin of the American Meteorological Society 80(2): 245-255. Available at: http://dx.doi.org/10.1175/15200477(1999)080<0245:TIOSCR>2.0.CO;2.

Yamaguchi DK (1991) A simple method for cross-dating increment cores from living trees. Canadian Journal of Forest Research 21(3): 414-416.

Zhang Z and Mann ME (2005) Coupled patterns of spatiotemporal variability in Northern Hemisphere sea level pressure and conterminous US drought. Geophysical Research Letters 110: D03108. 